Brazilian Journal

of Chemical

ISSN 0104-6632

Engineering

\title{
USE OF CALCINED LAYERED DOUBLE HYDROXIDES FOR THE REMOVAL OF COLOR AND ORGANIC MATTER FROM TEXTILE EFFLUENTS: KINETIC, EQUILIBRIUM AND RECYCLING STUDIES
}

\author{
T. P. F. Teixeira, S. F. Aquino ${ }^{*}$, S. I. Pereira and A. Dias \\ Departamento de Química, Universidade Federal de Ouro Preto, Campus Morro do Cruzeiro, \\ ICEB II, Sala 67, 35400-000, Ouro Preto - MG, Brazil. \\ E-mail: thaisa_700@hotmail.com; E-mail: simipereira2004@yahoo.com.br; \\ E-mail: anderson_dias@iceb.ufop.br \\ "E -mail: sergio@iceb.ufop.br
}

(Submitted: May 31, 2012 ; Revised: March 26, 2013 ; Accepted: March 26, 2013)

\begin{abstract}
This paper presents data for the synthesis and characterization of layer double hydroxides (LDH) and their use for color and chemical oxygen demand (COD) removal from effluents generated by a textile industry. Adsorption studies with raw and biologically treated (activated sludge) textile effluent showed that the pseudo-second order model best fitted the experimental data, leading to adsorption coefficients of 39.1 and $102.9 \mathrm{mgCOD} / \mathrm{gLDH}$ for raw and treated effluents, respectively. The best conditions for color and COD removal were obtained at lower values of temperature and $\mathrm{pH}\left(25^{\circ} \mathrm{C}\right.$ and $\left.\mathrm{pH} 7\right)$ and, in these conditions, an LDH dose of $10 \mathrm{~g} / \mathrm{L}$ resulted in color removal efficiencies of $56 \%$ for samples of raw and $66 \%$ for samples of treated effluent. Recycling studies indicated that the reuse of thermally treated LDH led to a progressive loss in the removal efficiencies of $\mathrm{COD}$ and color. The reduction was more pronounced with samples of the raw textile effluent. LDH characterization performed before and after each adsorption and regeneration experiment showed that there was no intercalation of dye molecules in the interlayer region of the $\mathrm{LDH}$, indicating that $\mathrm{COD}$ and color removal might be due to the adsorption of organic molecules onto the LDH surface.

Keywords: Color removal; Chemical oxygen demand (COD) removal; Textile effluent; LDH (Layered Double Hydroxides).
\end{abstract}

\section{INTRODUCTION}

Wastewater from textile industries contains significant amounts of organic dyes, especially of the azo-type, which impart a high color to the effluent. Some dyes and/or their degradation products might be carcinogenic and have mutagenic properties, especially those containing the azo-aromatic function as a chromophore, which leads to the formation of aromatic amines that are considered the main products from the biological cleavage of the $\mathrm{N}=\mathrm{N}$ bond (Guaratini and Zanoni, 2000). Generally, textile effluents are treated by the combination of conventional biological (activated sludge) and physicochemical (chemical coagulation, adsorption on activated carbon) processes. Although these processes have high efficiency in reducing the carbonaceous organic matter, they are not so efficient in color

*To whom correspondence should be addressed 
removal. The failure in the degradation of organic molecules responsible for the coloration is related to their complexity, variety and chemical nature (Guaratini and Zanoni, 2000). An option to complement the conventional biological treatment of textile effluents is the use of a physicochemical step of pre- or posttreatment. Several studies demonstrated that the group of hydrotalcites, which are layered double hydroxides (LDH) or anionic clays, are efficient materials to adsorb and/or intercalate anionic compounds such as sulphate dyes and surfactants, halides, sulfates, nitrates, silicates, chlorides, and polymers (Barriga et al., 2002; Bouraada et al., 2009; Bouraada et al., 2008; Cardoso et al., 2003; Cavani et al., 1991; Das et al., 2007; Das et al., 2006; Dias et al., 2011; Lazaradis et al., 2003; Lv et al., 2009; Lv et al., 2008b; Lv et al., 2008.; Seida and Nakano, 2002; Ulibarri et al., 1995).

The LDH have the formula $\left[\mathrm{M}^{+2}{ }_{1-\mathrm{x}} \mathrm{M}^{+3}{ }_{\mathrm{x}}(\mathrm{OH})_{2}\right]^{+\mathrm{x}}$ $\mathrm{A}^{-\mathrm{n}}{ }_{\mathrm{x} / \mathrm{n}} \cdot \mathrm{mH}_{2} \mathrm{O}$, where $\mathrm{M}^{+2}$ and $\mathrm{M}^{+3}$ represent divalent and trivalent metal cations; $\mathrm{A}^{-\mathrm{n}}$ is an anion with charge $-\mathrm{n} ; \mathrm{x}$ is the ratio $\mathrm{M}^{3+} /\left(\mathrm{M}^{2+}+\mathrm{M}^{3+}\right)$; and $m$ is the number of moles of water (Cavani et al., 1991; Dias et al., 2011). In particular, the LDH containing $\mathrm{Mg}^{2+}$ and $\mathrm{Al}^{3+}$ as divalent and trivalent cations, respectively, and carbonate as the interlayer anion are called hydrotalcites. The heat treatment of $\mathrm{LDH}$ leads to the formation of an oxi-hydroxide mixture (calcined LDH) of the constituent cations following the loss of interlayer carbonate and water. The calcined LDH formed can then be placed in contact with an anionic solution and the LDH containing the anion of interest is obtained through the regeneration of the layered structure. This process of regeneration of the layered structure after thermal decomposition is called 'memory effect' and can be used for removing and recovering anionic species from water and wastewater.

In this study, calcined LDH of the type MgAl$\mathrm{CO}_{3}$ were used for removing color and chemical oxygen demand (COD) from effluents generated by a textile industry; hence, this paper shows the application of LDH to treat a real industrial wastewater. In addition to obtaining thermodynamic data for the adsorption process, procedures for recycling the $\mathrm{LDH}$ via thermal decomposition were also investigated.

\section{EXPERIMENTAL}

The LDH was synthesized by the direct method of coprecipitation at constant $\mathrm{pH}$. Equation (1) represents the synthesis of hydrotalcite with a $\mathrm{Mg} / \mathrm{Al}$ ratio of 2/1 (Dias et al., 2011).

$$
\begin{aligned}
& 4 \mathrm{Mg}\left(\mathrm{NO}_{3}\right)_{2} \cdot 6 \mathrm{H}_{2} \mathrm{O}+2 \mathrm{Al}\left(\mathrm{NO}_{3}\right)_{3} \cdot 9 \mathrm{H}_{2} \mathrm{O} \\
& +\mathrm{Na}_{2} \mathrm{CO}_{3}+12 \mathrm{NaOH} \rightarrow \mathrm{Mg}_{4} \mathrm{Al}_{2}(\mathrm{OH})_{12} \mathrm{CO}_{3} \\
& .4 \mathrm{H}_{2} \mathrm{O}+14 \mathrm{NaNO}_{3}+38 \mathrm{H}_{2} \mathrm{O}
\end{aligned}
$$

For the synthesis of $20 \mathrm{~g}$ of $\mathrm{LDH}, 42.0907 \mathrm{~g}$ of $\mathrm{Mg}\left(\mathrm{NO}_{3}\right)_{2} \cdot 6 \mathrm{H}_{2} \mathrm{O}$ and $30.7903 \mathrm{~g}$ of $\mathrm{Al}\left(\mathrm{NO}_{3}\right)_{3} \cdot 9 \mathrm{H}_{2} \mathrm{O}$ were added to $100 \mathrm{~mL}$ of distilled water. This solution was then poured slowly into $100 \mathrm{~mL}$ of $\mathrm{Na}_{2} \mathrm{CO}_{3}$ $(1 \mathrm{M})$ and the $\mathrm{pH}$ of the resulting solution was measured and kept at $\mathrm{pH} 10$ using $\mathrm{NaOH}(2 \mathrm{M})$. The procedure of adding $\mathrm{NaOH}$ and monitoring the $\mathrm{pH}$ was carried out for $4 \mathrm{~h}$ under continuous stirring at $40{ }^{\circ} \mathrm{C}$ on a magnetic stirrer with heating. Subsequently, an incubator shaker was used to keep the reaction at $55^{\circ} \mathrm{C}$ and $200 \mathrm{rpm}$ for $20 \mathrm{~h}$. The resulting suspension was then vacuum filtered and dried at $50{ }^{\circ} \mathrm{C}$ in an oven to obtain an $\mathrm{LDH}$ of the $\mathrm{MgAl}-\mathrm{CO}_{3}$ type. Part of this material was heat-treated in an oven for $4 \mathrm{~h}$ at $500{ }^{\circ} \mathrm{C}$ and then kept in a vacuum desiccator. Such heat treatment led to the formation of calcined LDH, which was used in the subsequent tests.

To study the structural and morphological properties of the material before and after the adsorption experiments, the characterization techniques of specific surface area and porosity (BET), thermogravimetric analyses (TGA/DTG) and X-ray diffraction (XRD) were used as described by Vieira et al. (2009) and Dias et al. (2011). XRD analyses were performed using a Shimadzu XRD-6000 diffractometer, with graphite monochromator, nickel filter, $\mathrm{FeK} \alpha$ radiation $(\lambda=1.9360 \AA \hat{)}), 40 \mathrm{kV}$ and $20 \mathrm{~mA}$. A scan of $2-90^{\circ} 2 \theta$ at a rate of $2^{\circ} 2 \theta /$ minute was used and the

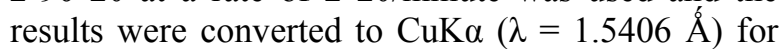
data processing. Thermogravimetric analyses (TGA/ DTG) were performed in a SDT 2960 equipment, using approximately $7 \mathrm{mg}$ of sample in an alumina crucible. The heating was from room temperature to $1.000{ }^{\circ} \mathrm{C}$, at a rate of $20{ }^{\circ} \mathrm{C} /$ minute under a $\mathrm{N}_{2}$ atmosphere. The measurements of specific surface area and porosity (BET and BJH methods) of the material in the powder form were carried out in a NOVA 1000 equipment. For that, $4 \mathrm{~g}$ of the sample was previously degassed at $150{ }^{\circ} \mathrm{C}$ for 2 hours and the parameters of interest were obtained using a nitrogen relative pressure in the range of 0.05 to 0.98 .

The batch experiments to assess the efficiency of LDH on color and COD removal from textile effluents, as well as to study its kinetics, and were carried out with samples of raw textile effluents 
(RTE1, RTE2 and RTE3) and biologically treated (by activated sludge process) effluents (BTE1, BTE2 and BTE3). The samples, collected in three different sampling campaigns, were kindly provided by the Itabirito Industrial Company - Itabirito, MG, Brazil.

Samples of raw and treated effluent were first filtered $(1.2 \mu \mathrm{m}$ glass fiber membranes) and then centrifuged for 20 minutes at $5.000 \mathrm{rpm}$ for the removal of suspended solids. The resulting supernatant $(100 \mathrm{~mL})$ was then submitted to adsorption tests in a shaker (Solab, mod. SL120/250) set at $200 \mathrm{rpm}$ for $24 \mathrm{~h}$ using different amounts of calcined LDH (50, 250, 750, 1000 and $2.000 \mathrm{mg}$ ). The adsorption tests with raw wastewater were carried out at $40{ }^{\circ} \mathrm{C}$, whereas with treated effluent $25^{\circ} \mathrm{C}$ was used, so that the conditions in which the raw and treated effluents are normally found could be reproduced. Samples collected before and after each batch test were centrifuged for $10 \mathrm{~min}$ at $5.000 \mathrm{rpm}$ (Excelsa model 206BL centrifuge, Fanem) before analyzing them for color and COD. COD analysis was performed according to the closed reflux method described in the Standard Methods for the Examination of Water and Wastewater (1998). Color analysis was carried out in a spectrophotometer (HP 8453) by fixing the wavelength at $250 \mathrm{~nm}$, which was found to be the wavelength of maximum absorbance for both effluents (raw and biologically treated) in all three sampling campaigns.

The adsorption (kinetics and equilibrium) of textile contaminants onto the calcined LDH was studied with randomly chosen samples of raw textile effluent (RTE3) and biologically treated effluent (BTE3). For each sample $750 \mathrm{mg}$ of calcined LDH was added into 10 flasks containing $50 \mathrm{~mL}$ of filtered effluent, which were then placed in a shaker (Solab, Mod. SL 120/250) set at $200 \mathrm{rpm}$ for $24 \mathrm{~h}$. At predetermined times samples were collected from the flasks, centrifuged (Excelsa model 206BL centrifuge, Fanem) at $5.000 \mathrm{rpm}$ for 10 minutes, and finally analyzed for color and COD.

The recycling capacity of the hydrotalcites was determined by cycles of adsorption-thermal decomposition-adsorption using the same filtered effluent samples and conditions described previously. For this, $1.000 \mathrm{mg}$ of calcined LDH was added to $100 \mathrm{~mL}$ of effluent and, after an adsorption period of $24 \mathrm{~h}$ at $200 \mathrm{rpm}$, the $\mathrm{LDH}$ was calcined $\left(500^{\circ} \mathrm{C}\right.$ for $\left.4 \mathrm{~h}\right)$ and used again for another adsorption cycle. A total of five cycles of adsorption-thermal decompositionadsorption was performed and the LDH dose (ratio of LDH mass to effluent volume) was kept constant throughout these experiments. The efficiency of color and COD removal was then determined after each cycle by means of color and COD analyses, as described before.

\section{RESULTS AND DISCUSSION}

Figure 1 presents the XRD patterns of the LDHs and their respective oxy-hydroxide mixture. A typical LDH XRD pattern shows a basal peak (001) related to the stacked layers; no basal peaks (hk0) associated with the organizational structure within the lamellae; and peaks $(0 \mathrm{kl})$ related to the internal layers.

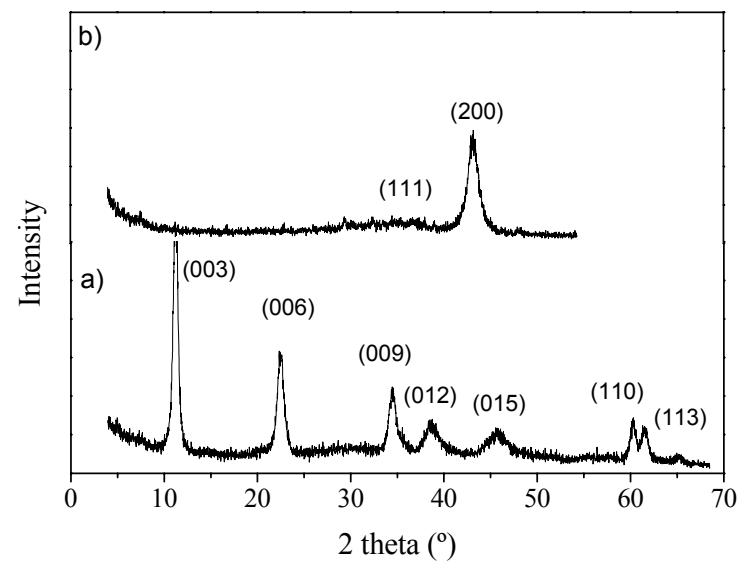

Figure 1: XRD patterns of the synthesized materials. a) LDH b) calcined LDH.

In the XRD pattern of a $\mathrm{LDH}$, the peaks (003), (006) and (009) are characteristic of a lamellar material and the lattice parameters $a$ and $c$ were calculated according to Pérez-Ramírez et al. (2001) for an hexagonal unit cell. The lattice parameter $a$ corresponds to the distance of the cations within the layers of the structure, whereas the parameter $c$ is related to the thickness of the layer and interlayer distance. Both lattice parameters can be calculated according to Eqs. (2) and (3), where the basal spacing $\mathrm{d}_{003}$ represents two lamellar layers and the interlayer of hydrated anions.

$\mathrm{a}=2 \mathrm{~d}_{110}$

$\mathrm{c}=3 \mathrm{~d}_{003}$

Scherrer's method (Eq. (4)) was used to determine the particle size $(t)$, where $\lambda$ is the wavelength (in $\mathrm{nm}$ ) of the X-rays used; B is the width at the half peak height; and $\theta_{\mathrm{B}}$ is the angle determined for the sample by Bragg's law (Zhao et al., 2009; Zhao et al., 2002). The LDH size was calculated as the 
average size between the first two better defined peaks $\left(\mathrm{d}_{003}\right.$ and $\left.\mathrm{d}_{006}\right)$. The $\mathrm{B}$ value was obtained from Eq. (5), where $B_{a m}$ is the half width of the peak, and the $\mathrm{B}_{\mathrm{pd}}$ value, characteristic of the XRD equipment, was set at 0.10 .

$\mathrm{t}=(0.9 \lambda) /\left(\mathrm{B} \cos \theta_{\mathrm{B}}\right)$

$\mathrm{B}^{2}=\mathrm{B}_{\mathrm{am}}{ }^{2}-\mathrm{B}_{\mathrm{pd}}{ }^{2}$

The basal spacing and lattice parameters calculated from the intensities and widths of the peaks led to values of $\mathrm{d}_{003}, a$, and c of, respectively, $7.9 \AA, 3 \AA$, $24 \AA$, which are consistent with the literature. For comparison, Palmer et al. (2009) reported $\mathrm{d}_{003}$ spacings of $7.8 \AA$, a value close to that found in this study and characteristic of LDH intercalated with carbonate ions. On the other hand, the calculated particle size $(\mathrm{t}=24.9 \mathrm{~nm})$ was lower than the particle sizes generally reported for this type of material (about $100 \mathrm{~nm}$ ). Smaller particle sizes mean larger widths of peaks, which are related to less crystalline materials, and this seems to be the case here.

Thermal decomposition of hydrotalcites is a complex sequence of steps involving dehydration, dehydroxylation (loss of lamellar hydroxyls) and loss of interlayer carbonate. Figure 2 shows the results of thermal analysis for HDL $\mathrm{MgAl}-\mathrm{CO}_{3}$. The steps and sequence of thermal decomposition of hydrotalcites can vary with the ratio of cations, (Hibino et al., 1995) but generally follow the same sequence. The first transition temperature and mass loss, below $200{ }^{\circ} \mathrm{C}$, is associated with the evaporation of adsorbed and intercalated water molecules. The other steps, between 200 and $500{ }^{\circ} \mathrm{C}$, refer to the decomposition of interlayer carbonate and hydroxyl groups of the lamellae (Hibino et al., 1995). Above $500{ }^{\circ} \mathrm{C}$, the lamella of the brucite-type structure collapses and a solid solution of mixed spinel $\left(\mathrm{MgAl}_{2} \mathrm{O}_{4}\right)$ and $\mathrm{MgO}$, or $\mathrm{Al}_{2} \mathrm{O}_{3}$ and $\mathrm{MgO}$ is irreversibly formed. The first mass-loss shown in Figure 2 indicates that the synthesized material has $0.058 \mathrm{~mol}$ of water per unit of hydrotalcite, implying that its structural formula is $\left[\mathrm{Mg}^{+2}{ }_{0.67} \mathrm{Al}^{+3}{ }_{0.33}(\mathrm{OH})_{2}\right]^{+0,33} \mathrm{CO}^{3-} .0 .058 \mathrm{H}_{2} \mathrm{O}$.

The specific surface area of LDH may reach 100 $\mathrm{m}^{2} / \mathrm{g}$, and the values found in this study $\left(10.7 \mathrm{~m}^{2} / \mathrm{g}\right.$ for $\mathrm{LDH}$ and $21.2 \mathrm{~m}^{2} / \mathrm{g}$ for calcined $\mathrm{LDH}$ ) were compatible with the range of values normally observed in the literature (Crepaldi et al., 2002). In addition, the pore sizes of the synthesized materials were $23 \mathrm{~nm}$, for $\mathrm{LDH}$, and $15 \mathrm{~nm}$, for the calcined $\mathrm{LDH}$, classifying both materials as mesoporous. The calcination leads to a greater number of micropores, resulting in a considerable increase in the surface area. This increase could be related to the formation of channels in the material during the evolution of water vapor and carbon dioxide (Cavani et al., 1991). The nitrogen adsorption/desorption isotherm (data not shown) indicated no hysteresis, thus suggesting the presence of cylindrical pores with open channels.

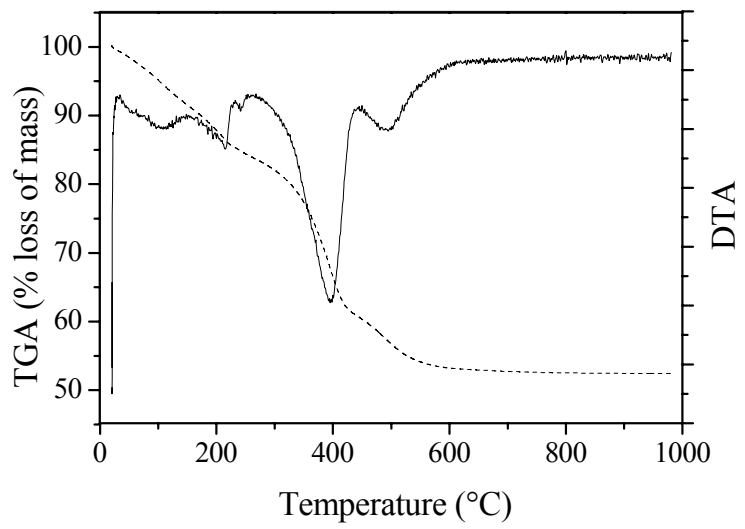

Figure 2: Thermal analysis of the synthesized LDH.

Figure 3 shows the color removal efficiency as a function of LDH mass added to a fixed volume $(100 \mathrm{~mL})$ of effluent.

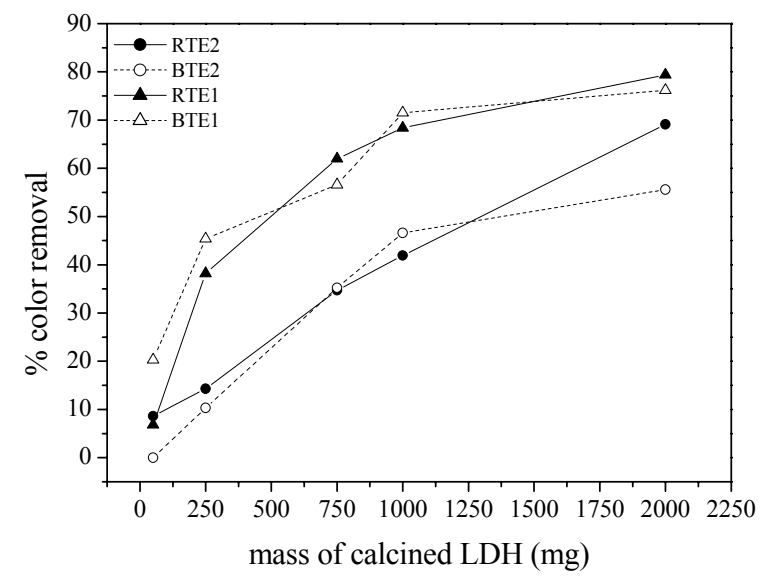

Figure 3: Color removal as function of the calcined LDH dose.

It can be seen that, for both raw (RTE) and biologically treated (BTE) effluents, the removal efficiency varied significantly between the samples collected at distinct dates, and this is due to the color change in the effluent. For instance, the raw textile effluent RTE2 showed an absorbance of 0.996 at 250 $\mathrm{nm}$, whereas for the effluent RTE1 it was $0.405 \mathrm{~nm}$ when diluted 5-fold. Figure 3 shows that, for both raw and treated effluent, the color removal tends to 
reach a plateau as the $\mathrm{LDH}$ dose is increased. At $\mathrm{LDH}$ doses of $10 \mathrm{~g} / \mathrm{L}$, the color removal efficiency varied from 40 to $68 \%$ for the raw effluent and from 45 to $72 \%$ for the treated effluent. By doubling the LDH dose the increase in color removal was less than $10 \%$ for either effluent.

Figure 4 shows the COD removal efficiency and Figure 5 the residual COD left in the raw and treated effluents that received different doses of $\mathrm{LDH}$. Figure 4 shows that, for samples of biologically treated effluents (BTE1, BTE2), the removal efficiency tended to reach a plateau when the dose was higher than $10 \mathrm{~g} / \mathrm{L}$. On the other hand, for most samples of the raw textile effluents (RTE1, RTE2), the COD removal seemed to be directly proportional to the dose, with significant enhancement of removal efficiency as the dose increased from $10 \mathrm{~g} / \mathrm{L}$ to $20 \mathrm{~g} / \mathrm{L}$. At the highest dose tested, the removal efficiencies varied from 50 to $80 \%$ for samples of raw effluent and from 60 to $70 \%$ for samples of biologically treated effluent. These results indicate that a high dose of LDH is needed to reach the performance of activated carbon for COD and color removal. For the sake of comparison, in a study of COD reduction from a dyeing effluent generated by a cotton textile mill, the use of a bamboo-based active carbon at a dose of $2 \mathrm{~g} / \mathrm{L}$ led to a COD reduction of $75 \%$ in $10 \mathrm{~h}$ of contact time for adsorption (Ahmad and Hameed, 2009).

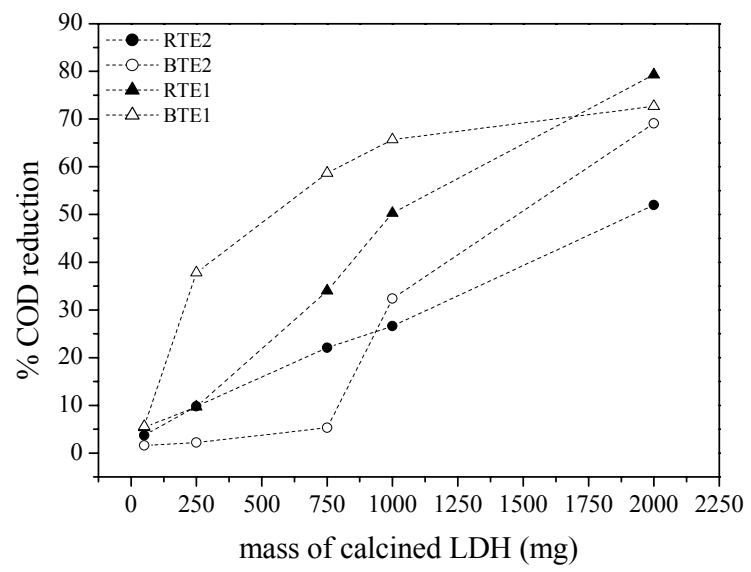

Figure 4: Efficiency of COD removal as a function of the calcined LDH dose.

$\mathrm{XRD}$ of the $\mathrm{LDH}$ placed in contact with the samples of raw (RTE) and treated (BTE) effluent at the dose of $10 \mathrm{~g} / \mathrm{L}$ showed the same pattern observed in Figure 1A. This indicates that the removal of color and COD was not accomplished by the intercalation of azo dyes or other larger organic molecules (e.g. anionic surfactant) since there were no significant changes in the lattice parameters $\left(\mathrm{d}_{003}=6.1 \AA\right.$; $a=2.4 \AA$, and $c=18.4 \AA$ - see Equations (2) and (3)). These results are in agreement with our previous results, (Teixeira et al., 2012; Vieira et al., 2009) which showed that the decolorization of azo dye (Remazol Golden Yellow RNL) solutions by LDH was due to adsorption rather than intercalation of the organic molecule. Figure 5 shows that a high dose of LDH $(20 \mathrm{~g} / \mathrm{L})$ is necessary to place the raw effluent samples (RTE) within the discharge limits for the parameter of COD, which is $250 \mathrm{mg} / \mathrm{L}$ for textile effluents, as defined in the Minas Gerais State Environmental Legislation (COPAM /CERH 01/2008). For the effluent submitted to the biological treatment of activated sludge (BTE), a calcined LDH dose eight times lower $(2.5 \mathrm{~g} / \mathrm{L})$ was sufficient to maintain the COD within the discharge limit for two out of the three samples analyzed.

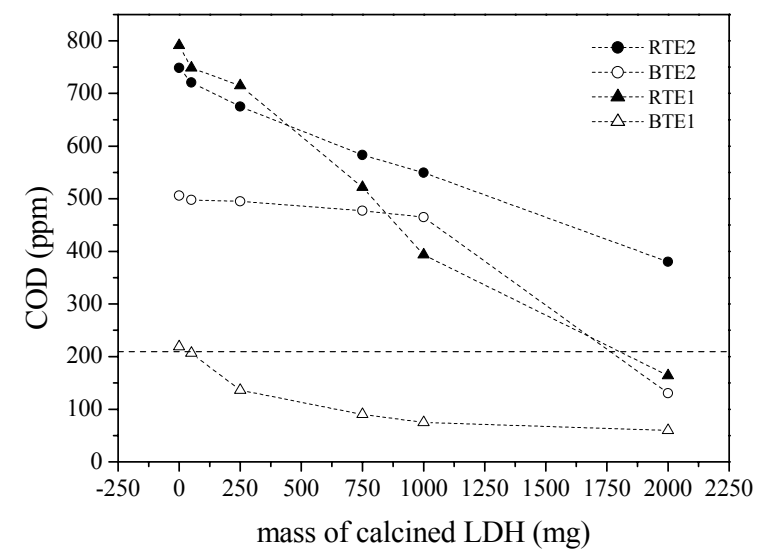

Figure 5: COD removal with the addition of calcined LDH.

Figure 6 presents the kinetics of COD removal for both effluents (RTE3 and BTE3) treated with a $\mathrm{LDH}$ dose of $15 \mathrm{~g} / \mathrm{L}$. It can be seen that, for the biologically treated effluent (BTE3), the maximum COD adsorption capacity, reached after $\sim 6 \mathrm{~h}$ of contact, was $\sim 30 \mathrm{mg} / \mathrm{g}$, whereas for the raw textile effluent (RTE3) the adsorption capacity was much higher $(\sim 85 \mathrm{mg} / \mathrm{g})$, but the equilibrium was reached at a significantly higher time $(\sim 15 \mathrm{~h})$. Table 1 shows that the experimental data fit best the pseudo-second order model, and the $\mathrm{K}_{2}$ values obtained indicate that the adsorption/intercalation of COD on LDH was about 6 times faster with the biologically treated effluent compared with the raw industrial effluent. As the doses required to achieve the established COD discharge limit is considerably lower with the biologically treated effluent, it seems more feasible to use LDH adsorption as a post-treatment unit to 
complement the activated sludge treatment in the removal of color and COD. The use of $\mathrm{LDH}$ to treat raw textile wastewater would imply that aerobic biodegradable compounds (e.g., anionic surfactants, starch) might be adsorbed/intercalated, leading to higher LDH doses and contact times, which would considerably increase treatment operational costs.

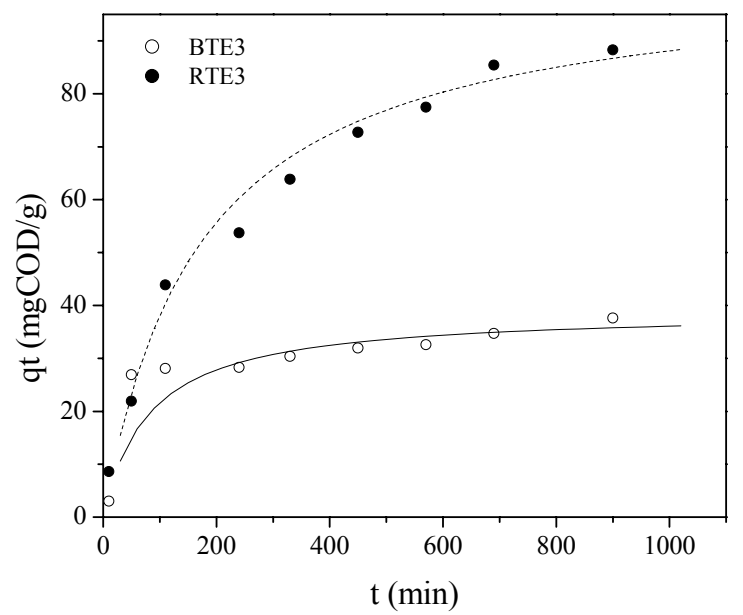

Figure 6: Kinetic study of COD removal with a LDH dose of $15 \mathrm{~g} / \mathrm{L}$.

Table 1: Kinetic parameters of the pseudo-second order model obtained for $\mathrm{LDH}$ removing COD from raw textile effluent (RTE3) and biologically treated effluent (BTE3).

\begin{tabular}{|c|c|c|c|}
\hline $\begin{array}{c}\text { Sample } / \\
\text { parameter }\end{array}$ & $\begin{array}{c}\mathbf{Q e} \\
\text { (mg/g) }\end{array}$ & $\begin{array}{c}\mathbf{K}_{\mathbf{2}} \\
\text { (g/mg.min) }\end{array}$ & $\mathbf{R}^{\mathbf{2}}$ \\
\hline RTE03 & 102.9 & $5.70 \mathrm{E}-05$ & 0.9935 \\
\hline BTE03 & 39.1 & $3.30 \mathrm{E}-04$ & 0.9934 \\
\hline
\end{tabular}

The results of the recycling capacity study carried out with samples of raw (RTE3) and biologically treated (BTE3) effluents are presented in Figures 7 and 8 . Figure 7 shows that, for the raw effluent, there was a loss of $\sim 42 \%$ in the COD removal after the $1^{\text {st }}$ thermal regeneration, which progressively increased until the $5^{\text {th }}$ cycle, where the removal loss reached $58 \%$. For the biologically treated effluent the loss after the $1^{\text {st }}$ cycle was lower $(\sim 37 \%)$ and remained around $40 \%$ until the $3^{\text {rd }}$ cycle, from which point it increased to reach a total loss of $60 \%$ after the $5^{\text {th }}$ cycle. The loss of COD removal efficiency was steeper and higher with the raw effluent, indicating a larger amount of adsorbed/intercalated compounds that could not be decomposed by the thermal treatment $\left(500{ }^{\circ} \mathrm{C}\right.$ for $\left.4 \mathrm{~h}\right)$. Examples of such compounds include azo dyes, which do not decompose completely at $500{ }^{\circ} \mathrm{C}$, (Teixeira et al., 2012; Vieira et al.,
2009) and chloride and hydroxide ions, which are present in high concentrations in the textile effluent. Although anions like chloride and hydroxide do not themselves contribute to the COD result, their adsorption/intercalation would obviously preclude the removal of oxidizable organics in the COD test, thereby reducing the COD removal efficiency.

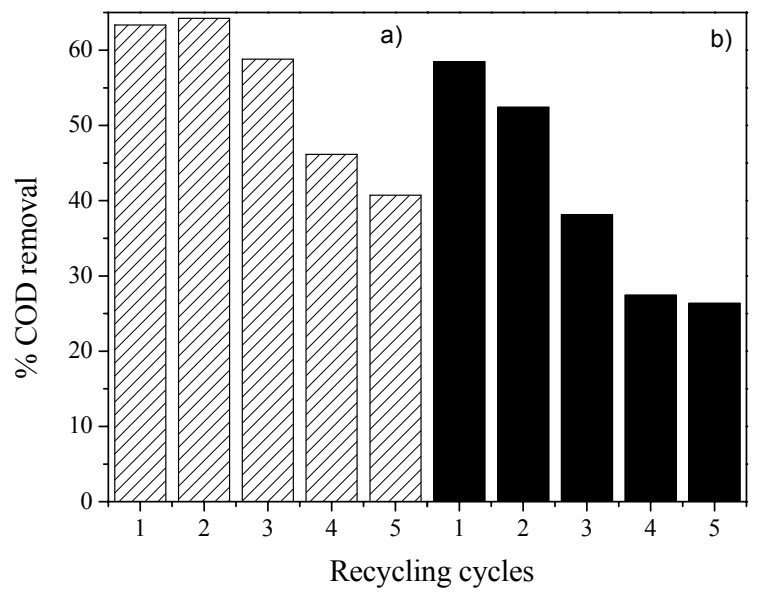

Figure 7: Loss of COD removal efficiency after each cycle of adsorption-thermal regeneration-adsorption using LDH with treated (a) and raw (b) effluent.

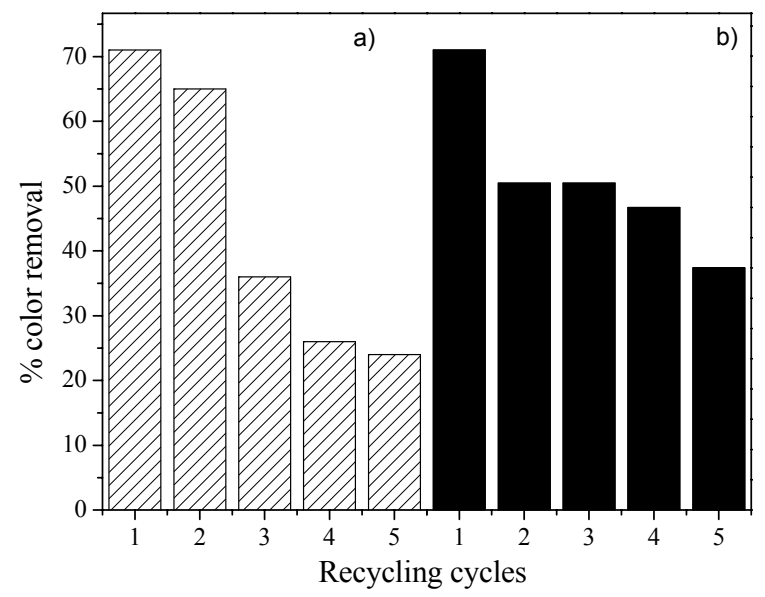

Figure 8: Loss of color removal efficiency after each cycle of adsorption-thermal regeneration-adsorption using LDH with treated (a) and raw (b) effluent.

As far as the color parameter is concerned, Figure 8 shows that the same pattern of progressive loss in the removal efficiency was observed. For the raw effluent samples, the loss started at 30\% ( $1^{\text {st }}$ cycle) and remained at $\sim 50 \%$ until the $4^{\text {th }}$ cycle, before further increasing to $62 \%$ loss at the $5^{\text {th }}$ cycle. For the biologically treated effluent, the loss in removal efficiency was more steep and varied from $30 \%\left(1^{\text {st }}\right.$ 
cycle) to $75 \%$ ( $5^{\text {th }}$ cycle). This behavior might be related to the fact that the biological treatment (activated sludge) employed in the textile industry is not efficient in removing color from the raw effluent. As a result, the biologically treated samples still had considerable amounts of anionic organics (azo dyes and their degradation products) and inorganics such as sulfate ions (due to $\mathrm{pH}$ neutralization with sulfuric acid prior to biological treatment) which do not decompose at $500{ }^{\circ} \mathrm{C}$. The results presented in Figures 7 and 8 corroborate the conclusion made before that it would be more advantageous to use $\mathrm{LDH}$ to remove the residual color and COD of the biologically treated effluent. In this way, LDH addition could be employed as a post-treatment to complement the biological treatment in the removal of recalcitrant organics such as azo dyes, chloride and sulfate.

\section{CONCLUSIONS}

Adsorption studies with raw and biologically treated (activated sludge) textile effluent samples showed that the best conditions for color and COD removal were obtained at lower values of temperature $\left(25^{\circ} \mathrm{C}\right)$ and $\mathrm{pH}(7)$. The pseudo-second order model best fitted the experimental data, yielding maximum organic matter removal capacities of 39.1 and $102.9 \mathrm{mgCOD} / \mathrm{gLDH}$ for raw and biologically treated effluents, respectively. The study showed that the thermal regeneration of LDH resulted, after five cycles, in losses in the removal capacity that varied from $35 \%$ to $68 \%$ for COD and from 50 to $67 \%$ for the color parameter. An LDH dose of $10 \mathrm{~g} / \mathrm{L}$ resulted in color removal efficiencies varying from $56 \%$ (raw effluent) to $66 \%$ (treated effluent) and, for the biologically treated effluent, a calcined LDH dose eight times lower $(2.5 \mathrm{~g} / \mathrm{L})$ was sufficient to maintain the COD within the discharge limit for most of the samples analyzed. Characterization analyses performed before and after each adsorption and regeneration experiment showed that the dye molecules and other anions were not intercalated in the interlayer region of $\mathrm{LDH}$, indicating that the COD and color removal was due to the adsorption of organic pollutants onto the LDH surface.

\section{ACKNOWLEDGEMENTS}

The authors would like to thank the following Brazilian agencies for their financial support: $\mathrm{CNPq}$, FAPEMIG and CAPES.

\section{REFERENCES}

Ahmad, A. A. and Hameed, B. H., Reduction of COD and color of dyeing effluent from a cotton textile mill by adsorption onto bamboo-based activated carbon. Journal of Hazardous Materials, 172, p. 1538-1543 (2009).

Barriga, C., Pavlovic, I., Ulibarri, M. A., Hermosin, M. C. and Cornejo, J., Hydrotalcites as sorbent for 2,4,6-trinitrophenol: Influence of the layer composition and interlayer anion. Journal of Materials Chemistry, 12, p. 1027-1034 (2002).

Bouraada, M., Belhafaoui, F. and Ouali, M. S., Sorption study of an acid dye from an aqueous solution on modified Mg-Al layered double hydroxides. Journal of Hazardous Materials. 163, p. 463-467 (2009).

Bouraada, M., Lafjah, M. and Ouali, M. S., Basic dye removal from aqueous solutions by dodecylsulfate and dodecyl benzene sulfonate-intercalated hydrotalcite. Journal of Hazardous Materials, 153, p. 911-918 (2008).

Cardoso, L. P., Tronto, J., Crepaldi, E. L. and Valim, J. B., Removal of benzoate anions from aqueous solution using $\mathrm{Mg}-\mathrm{Al}$ layered double hydroxides. Molecular Crystals and Liquid Crystal, 390, p. 49-56 (2003).

Cavani, F., Trifiri, F. and Vaccari, A., Hydrotalcitetype anionic clays: Preparation, properties and applications. Catalysis Today, 11, p. 173-301 (1991).

Crepaldi, E. L., Tronto, J., Cardoso, L. P. and Valim, J. B., Sorption of terephthalate anions by calcined and uncalcined hydrotalcite-like compounds. Colloids and Surfaces. A: Physicochemical and Engineering Aspects, 211, 103-114 (2002).

Das, J., Patra, B. S., Baliarsingh, N. and Parida, K. M., Adsorption of phosphate by layered double hydroxides in aqueous solutions. Applied Clay Science, 32, p. 252-260 (2006).

Das, J., Patra, B. S., Baliarsingh, N. and Parida, K. M., Calcined $\mathrm{Mg}-\mathrm{Fe}-\mathrm{CO}_{3} \mathrm{LDH}$ as an adsorbent for the removal of selenite. Journal of Colloid and Interface Science, 316, p. 216-223 (2007).

Dias, A., Cunha, L. and Vieira, A. C., Synthesis and properties of $\mathrm{A}_{6} \mathrm{~B}_{2}(\mathrm{OH})_{16} \mathrm{C}_{12} \cdot 4 \mathrm{H}_{2} \mathrm{O}(\mathrm{A}=\mathrm{Mg}, \mathrm{Ni}, \mathrm{Zn}$, $\mathrm{Co}, \mathrm{Mn}$ and $\mathrm{B}=\mathrm{Al}, \mathrm{Fe}$ ) materials for environmental applications. Materials Research Bulletin, 46, p. 1346 (2011).

Guaratini, C. C. I. and Zanomi, M. V. B., Textile dyes. Química Nova, 23, p. 71-78 (2000).

Hibino, T., Yamashita, Y., Kosuge, K. and Tsunashima, A., Decarbonation behaviour of $\mathrm{Mg}-\mathrm{Al}-\mathrm{CO}_{3}$ hydrotalcite-like compounds during heat treatment. Clays and Clay Minerals, 43, 427 (1995).

Lazaridis, N. K., Sorption removal of anions and 
cations in single batch systems by uncalcined and calcined $\mathrm{Mg}-\mathrm{Al}-\mathrm{CO}_{3}$ hydrotalcite. Water, Air and Soil Pollution, 146, p. 127-139 (2003).

Lv, L., Wang, Y., Wei, M., Cheng, J., Bromide ion removal from contaminated water by calcined and uncalcined $\mathrm{MgAl}-\mathrm{CO}_{3}$ layered double hydroxides. Journal of Hazardous Materials, 152, p. 1130-1137 (2008).

Lv, L., Sun, P., Wang, Y., Du, H. and Gu, T., Phosphate removal and recovery with calcined layered double hydroxides as an adsorbent. Phosphorus, Sulfur and Silicon and the Related Elements, 183, p. 519-526 (2008).

Lv, L., Sun, P., Gu, Z., Du, H., Pang, X., Tao, X., $\mathrm{Xu}, \mathrm{R}$. and $\mathrm{Xu}, \mathrm{L}$. , Removal of chloride ion from aqueous solution by $\mathrm{ZnAl}-\mathrm{NO}_{3}$ layered double hydroxides as anion- exchanger. Journal of Hazardous Materials, 161, p. 1444-1449 (2009).

Palmer, S. J., Nguyen, T. and Frost, R. L., Thermal decomposition of hydrotalcites with variable cationic ratios. Coordination Chemistry Review, 253, p. 250 (2009).

Pérez-Ramírez, J., Mul, G. and Moulinjn, J. A., In situ Fourier transform infrared and laser Raman spectroscopic study of the thermal decomposition of $\mathrm{Co}-\mathrm{Al}$ and Ni-Al hydrotalcites. Vibrational Spectroscopy, 27, 1, p. 75-88 (2001).

Seida, Y., Nakano, Y., Removal of phosphate by layered double hydroxides containing iron. Water Reserch, 36, 5, p. 1306-1312 (2002).

Standard Methods for the Examination of Water and
Wastewater, 20th Ed., American Public Health Association/American Water Works Association/ Water Environment Federation, Washington DC, USA (1998).

Teixeira, T. P. F., Pereira, S. I., Aquino, S. F., Dias, A., Calcined layered double hydroxides for decolorization of azo dye solutions: Equilibrium, kinetics, and recycling studies. Environmantal Engineering Sciece, 29(7), p. 685-692 (2012).

Ulibarri, M. A., Pavlovic, I., Hermosin, M. C. and Cornejo, J., Hydrotalcite-like compounds as potential sorbents of phenols from water. Applied Clay Science, 10, p. 131-145 (1995).

Vieira, A. C., Moreira, R. L., Dias, A., Raman scattering and Fourier-transform infrared spectroscopy of $\mathrm{Me}_{6} \mathrm{~A}_{12}(\mathrm{OH})_{16} \mathrm{Cl}_{2} \cdot 4 \mathrm{H}_{2} \mathrm{O}(\mathrm{Me}=\mathrm{Mg}, \mathrm{Ni}$, $\mathrm{Zn}, \mathrm{Co}$, and $\mathrm{Mn})$ and $\mathrm{Ca}_{2} \mathrm{Al}(\mathrm{OH})_{6} \mathrm{Cl}_{2} 2 \mathrm{H}_{2} \mathrm{O}$ hydrotalcites. The Journal of Physical Chemistry C, 113, p. 13358-13368 (2009).

Zhao, L., Miao, J., Wang, H., Ishikawa, Y. and Feng, Q., Synthesis and exfoliation of layered hydroxide zinc aminobenzoate compounds. Nippon Seramikkusu Kyokai Gakujutsu Ronbunshi/Journal of the Ceramic Society of Japan, 117, 1370, p. 1115-1119 (2009).

Zhao, Y., Li, F., Zhang, R., Evans, D. G. and Duan, X., Preparation of layered double-hydroxide nanomaterials with a uniform crystallite size using a new method involving separate nucleation and aging steps. Chemistry of Materials, 14, 10, p. 4286-4291 (2002). 